\title{
Monitoring and distribution modelling of invasive species along riverine habitats at very high resolution
}

\author{
Patrice Descombes • Blaise Petitpierre • Eric Morard • \\ Michael Berthoud · Antoine Guisan · Pascal Vittoz
}

Received: 22 February 2014/ Accepted: 12 August 2016/Published online: 18 August 2016

(C) Springer International Publishing Switzerland 2016

\begin{abstract}
Monitoring and species distribution models (SDMs) are increasingly used to support conservation planning but are rarely projected at a very high resolution for conservation management. In this study, we compared the population distribution and size of five invasive plant species along an $18 \mathrm{~km}$ alluvial system in Switzerland, over a period of 11 years. Exhaustive inventories of past (2001) to current (2012) populations showed a massive increase in invaded areas over the eleven years. Impatiens glandulifera and Reynoutria japonica were the species with the largest increases in population number and size. The ecological preferences of each species were then
\end{abstract}

Patrice Descombes and Blaise Petitpierre shares co-first authorship.

Antoine Guisan and Pascal Vittoz shares co-last authorship.

Electronic supplementary material The online version of this article (doi:10.1007/s10530-016-1257-4) contains supplementary material, which is available to authorized users.

P. Descombes · B. Petitpierre · A. Guisan · P. Vittoz ( $\square)$ Department of Ecology and Evolution, University of Lausanne, 1015 Lausanne, Switzerland

e-mail: pascal.vittoz@unil.ch

P. Descombes

Landscape Ecology, Institute of Terrestrial Ecosystems, ETH Zürich, 8092 Zurich, Switzerland

P. Descombes

Swiss Federal Research Institute WSL, 8903 Birmensdorf, Switzerland modelled at $1 \mathrm{~m}$ resolution, using environmental variables expressing topography, disturbances, dispersal, soil texture and light availability. SDMs successfully depicted the niches at very high resolution. Some of the important predictors (e.g., canopy density, distance to river) would have been unhelpful at a coarser resolution. From these very-high-resolution models, we predicted the potential distribution and abundance of species and derived two indices indicating the amount of habitat still available for future species colonisation, crucial information for management. Large, empty areas were predicted to be suitable for each species, suggesting that the observed increase in population size may continue in the future. The two proposed range-filling indices and abundance models may be used efficiently in future studies at very fine resolution to prioritise eradication efforts in previously invaded areas and controls in areas at high risk of invasion. To our knowledge, this is the first

E. Morard

BEB SA, Ch. des Artisans 6, 1860 Aigle, Switzerland

M. Berthoud · A. Guisan · P. Vittoz

Institute of Earth Surface Dynamics, University of

Lausanne, 1015 Lausanne, Switzerland 
study investigating the efficiency of SDMs to predict invasions at such a fine resolution.

Keywords Buddleja davidii . Ecological niche modelling · Fine resolution · Floodplain · Helianthus tuberosus - Impatiens glandulifera · Population size · Prunus laurocerasus - Reynoutria japonica . Species distribution models $\cdot$ Switzerland

\section{Introduction}

The invasion of natural communities by non-native species is one of the major causes of biodiversity loss, along with habitat decline (Keller et al. 2012). Invasive plant species can alter nutrient cycling (Ehrenfeld 2003) and can outcompete the native flora by shading out native species (Lake and Leishman 2004). Although mostly associated with human activity around urban areas (Hulme 2003), invasive species are also known to be very abundant along rivers, where water flow acts as a dispersal vector, particularly when flooding occurs (Tickner et al. 2001). Such disturbances by water creates gaps in the forb cover, providing suitable habitats and favourable nutrient conditions for the establishment of invasive species seedlings (Renöfält et al. 2005; Maskell et al. 2006; Miller and Matlack 2010).

Human activity (e.g., river containment) during the nineteenth and twentieth centuries drastically decreased the number of rivers presenting a natural dynamic (alluvial areas) in Switzerland (Lachat et al. 2010). Because these habitats are also considered to be hotspots of native species diversity (Ward et al. 2002), and at the same time are at a high risk of invasion by exotic plants (i.e., represent conflict areas; Vicente et al. 2011), it is urgently necessary to implement conservation actions to limit the impact of invasive species in these rare and fragile ecosystems.

Biological invasions are characterised by a slow initial spread (lag phase) during which species occur only in a few localities, followed by a fast spread (exponential phase) and a third phase of decelerating expansion (Pysek and Hulme 2005). However, invasion processes comprise both the increase in number of individuals within local populations and the colonisation of new areas on larger scales (Pysek and Hulme 2005). Thus, the scale at which the biological invasion is assessed can lead to different interpretations, and the population growth may be underestimated if the assessment is limited to the record of established populations in new areas (range expansion). Studies reporting colonisation of new areas by invasive plant species are numerous (e.g., Pysek and Prach 1993; Pysek and Hulme 2005), but examples of population monitoring at the local scale are much rarer (e.g., Kasperek 2004) despite their crucial importance for understanding colonisation processes (Pysek and Hulme 2005).

Furthermore, early prevention actions in sites likely to be invaded is more effective than attempts to eradicate well-established infestations (Leung et al. 2002; Guillera-Arroita et al. 2014). Species distribution models (SDMs; Guisan and Thuiller 2005) represent potentially useful tools in this regard (Guisan et al. 2013). They relate environmental characteristics (e.g., climatic and topographic variables) to the current geographical distribution of species in terms of presence/absence or abundance to fit species' realised niches, and they predict the distribution of suitable habitats. SDMs can also prove useful in conservation by detecting and ranking environmental variables affecting the distribution and fitness of species and by helping managers visualise the invasive potential of the analysed species (Guisan and Thuiller 2005). Abundance SDMs may prove especially useful here, as a proxy to assess the potential impact of invasive populations (Ricciardi 2003; Kulhanek et al. 2011; Bradley 2013).

During the past decade, most SDM studies investigated the distribution of invasive species at coarse resolution $(\geq 100 \mathrm{~m})$ across large areas, where climatic factors are determining factors in shaping the species distributions. Whereas global SDMs using topo-climatic variables at coarser resolution are useful for pre-border prevention and to depict coarse suitable areas (e.g., at the regional or national scales; Thuiller et al. 2005; Koop et al. 2012), post-border management of biological invasions must ultimately be performed at finer resolution. Indeed, mapping at coarse resolution tends to overestimate the potential distribution of invasive species and to inadequately describe the spatial structure of invasions at the local population scale (Hulme 2003). Moreover, changes in habitat conditions can occur over short distances, especially in heterogeneous environments such as alluvial areas. Thus, finer-resolution models $(<10 \mathrm{~m})$ 
are required for conservation efforts, planning and management, which need precise knowledge of both the ecology and the distribution of the species (Heinänen et al. 2012; Growns et al. 2013). To our knowledge, no studies to date have tested the efficiency of SDMs to predict biological invasions by using environmental predictors and species observations at such a fine resolution.

By comparing past population distributions to current exhaustive inventories, we quantified changes in population number and size for four invasive species (Reynoutria japonica, Impatiens glandulifera, Helianthus tuberosus and Buddleja davidii) along $18 \mathrm{~km}$ of a Swiss river. We then fitted the realised niches of the aforementioned species and Prunus laurocerasus using existing data within very-highresolution ( $1 \mathrm{~m})$ SDMs. Accordingly, the aims of the study were (1) to quantify the changes in population size of invasive plant species along the river between 2001 and 2012, (2) to identify the environmental variables explaining species presence and abundance at very high resolution, and (3) to target the areas potentially vulnerable to future invasions. Finally, the findings are discussed in the context of management of protected areas with regard to invasive plant species.

\section{Materials and methods}

\section{Study area}

The study area is located in western Switzerland along an $18 \mathrm{~km}$ section of the Venoge River $(46.57 \mathrm{~N}, 6.53$ E; Fig. 1). This alluvial area, ranging from 370 to $450 \mathrm{~m}$ a.s.l., is located in the colline vegetation belt, naturally composed of deciduous forests dominated by Quercus robur and Fraxinus excelsior. The Venoge undergoes heavy flooding mainly in winter, regularly modifying the river's course and maintaining the diversity of alluvial vegetation, a situation rarely sustained on the Swiss Plateau. This conservation value is recognised by the National Inventory of Natural Alluvial Areas (Swiss Federal Office for the Environment, FOEN, http://www.bafu.admin.ch), which includes two protected areas within the study area. Despite this important national conservation status, no particular invasive plant species management plan has yet been established for this particular study area. To focus the inventory only on the invasive

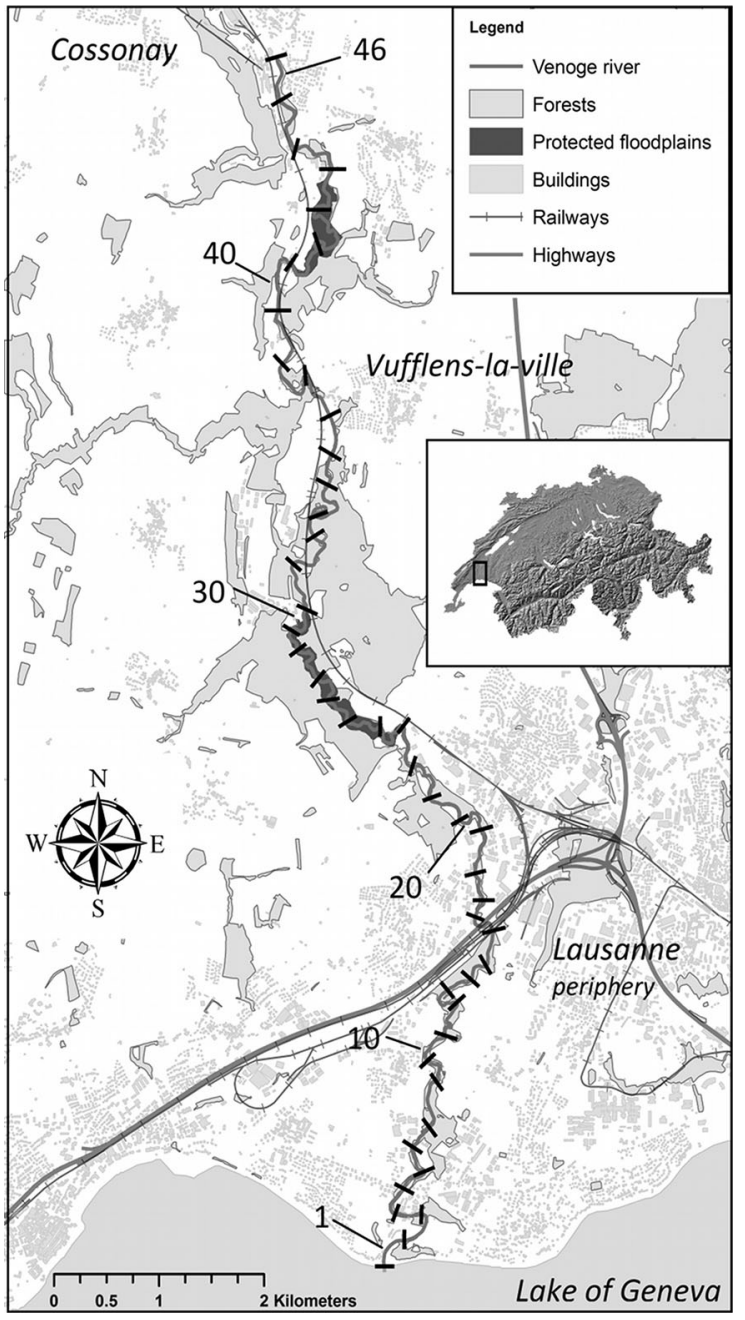

Fig. 1 Location of the study area in western Switzerland. Study area is limited by the potentially flooded zones along $18 \mathrm{~km}$ of the Venoge River, split into 46 sectors of approximately $400 \mathrm{~m}$ in length

species in an alluvial dynamic context, the study area was bounded either by a width of $30 \mathrm{~m}$ on each side of the river or an elevation of $2 \mathrm{~m}$ above the mean water level with a $1 \mathrm{~m}$ resolution digital elevation model (DEM, Office of Land Information OIT, www.vd.ch/ oit) using ArcGIS 9.3 software (ESRI, Redlands, CA, USA, 2008).

\section{Population inventory}

Between July and September 2012, we inventoried the entire populations of five invasive plant species along the study area: Reynoutria japonica Houtt., Impatiens glandulifera Royle, Helianthus tuberosus L., Buddleja 
davidii Franch. and Prunus laurocerasus L. (see Table S3 for a summary of their basic life history characteristics). R. x bohemica Chrtek \& Chrtková (hybrid of $R$. japonica and $R$. sachalinensis (F. Schmidt) Nakai) was included in $R$. japonica as individuals exhibited intermediate traits, making species identification questionable. These five species are listed as invasive on the Black list or Watch list of the Swiss Federal Office for the Environment (http:// www.infoflora.ch). In a previous inventory (see below), the river was divided into 46 sectors, each approximately $400 \mathrm{~m}$ long (Fig. 1). We invested approximately $9 \mathrm{~h}$ in a census of the invasive species populations of each sector. Special attention was taken to detect small populations because detection rate increases with abundance (e.g., McCarthy et al. 2013). Moreover, an additional survey of $1-2 \mathrm{~h}$ per sector was performed at the end of the field season (September) to detect individual overlooked populations. All species are visible enough to be seen from a reasonable distance, making it feasible to assume that all the individuals were seen and mapped. Although we did not collect data in a way that allows the detection process to be modelled, we spent enough effort in each sector so that detection can be assumed to be nearly perfect (Lahoz-Monfort et al. 2014).

A population was defined as a set of individuals less than five metres from each other. For each population, the precise location of the population centre was recorded with a Trimble GeoXH handheld GPS connected to a Tornado external antenna (precision $<0.5 \mathrm{~m}$ ). These coordinates were then further used as the species occurrences in the SDM. The area below the plant canopy was estimated in $\mathrm{m}^{2}$, and the number of individuals was precisely counted for small populations or estimated for large populations $(>300$ individuals). An individual was defined as a single stem for H. tuberosus and I. glandulifera and as a bush for $B$. davidii and $P$. laurocerasus. Because $R$. japonica forms dense populations consisting of groups of stems, it would have been laborious and unreliable to perform a count of all the stems; an individual was defined as a group of stems $(<15 \mathrm{~cm}$ from one another).

Historical data

An inventory performed during the summer of 2001 along the same study area already reported the population distribution of $R$. japonica, I. glandulifera, H. tuberosus and B. davidii (Morard 2001, unpublished data). As stated above, the river was divided into 46 sectors for this inventory, each approximately $400 \mathrm{~m}$ long (Fig. 1). Populations of $R$. japonica and $B$. davidii were inventoried and classified into five size classes according to the number of individuals (class 1 , 1-4 individuals; 2, 5-9; 3, 10-49; 4, 50-99; 5, 100). In addition, the areas $\left(\mathrm{m}^{2}\right)$ occupied by the populations were estimated. H. tuberosus and I. glandulifera individuals were counted for each sector. The populations were roughly located on a map $(1: 25,000)$ without the use of a GPS device.

We compared the density (individuals per linear metre of river) of the four species within each sector. $R$. japonica and B. davidii densities for 2001 were extrapolated from the population size (classes 1-5) following three conversions: minimum, median and maximum numbers of individuals in size classes. These conversions were performed to define the possible range of changes of density between 2001 and 2012. Because the number of individuals was not estimated in the large populations of the 2001 inventory (class 5 , i.e., $\geq 100$ individuals), we estimated the mean density (individuals $/ \mathrm{m}^{2}$ ) in populations of class 4 sampled in 2012 and extrapolated to the area estimated for populations of class 5 sampled in 2001. Thus, we obtained an estimate of the number of individuals for the large populations in the 2001 inventory. Sector densities between 2001 and 2012 were compared using a non-parametric paired test (Wilcoxon signed rank test). For three species $(R$. japonica, I. glandulifera and $B$. davidii), some populations observed in 2001 could be located again in 2012 on the basis of the original map or photograph archives, and changes in population size could be assessed at the population level. These changes were also assessed using Wilcoxon signed rank tests.

\section{Environmental variables}

To depict the ecological niche of each species, we initially selected 15 environmental variables that could explain the species distribution at very high resolution (Table S3). Variables were provided by the Federal Office of Topography (www.swisstopo. admin.ch) and were derived from GIS layers using ArcGIS 9.3 software (ESRI, Redlands, CA, USA, 2008) with $1 \mathrm{~m}$ resolution, except soil texture and 
canopy density at population sites, which were measured in the field. Environmental variables were sampled at the coordinates recorded for each population. Soil texture was visually estimated (in percentages) at a depth of $5 \mathrm{~cm}$ for the following four characteristics: organic matter, fine mineral sediments $(<2 \mathrm{~mm})$, small stones $(2-75 \mathrm{~mm})$ and large stones $(>75 \mathrm{~mm})$. These visual estimations were then corrected using a standardised measured reference (see Appendix S1). Topographic variables, including slope (degree) and surface curvature (degree of convexity/concavity), were derived from the DEM at $1 \mathrm{~m}$ resolution (elevation uncertainty $\pm 0.5 \mathrm{~m}$ ) using the "slope" and "curvature" functions in ArcGIS 9.3 software (ESRI, Redlands, CA, USA, 2008), which can be considered as proxies for soil stability and wetness. Variables related to dispersal included distance to the river, distance to major roads, distance to forest roads, distance to railway lines, density of habitation (including farms; $\%$ of the area occupied by habitations) and density of industrial areas (\%) calculated for a circular window of 500 m radius by using Swiss land cover data (http://www.geostat.admin.ch) for the year 2009. Disturbance variables included river sinuosity (index) and river curvature (index). River sinuosity corresponds to the ratio between the $100 \mathrm{~m}$ along the watercourse separating two points and the shortest straight path connecting those points. A high sinuosity indicates that the river presents a tortuous watercourse in which open areas and sedimentation processes are favoured (Tickner et al. 2001; Ward et al. 2002). River curvature corresponds to the radius of the river curves. A positive value of curvature corresponds to the internal shore of the curves, where sedimentation is important (i.e., inside meander), thus providing ideal areas for pioneer colonisers, whereas a negative value corresponds to the external shore of the curves, where erosion is high (i.e., outside meander). Both sinuosity and curvature were calculated for each metre along both riversides. Note that distance to the river can also be seen as a proxy of river disturbance. We measured the canopy density with two techniques. First, canopy closure was measured directly in the field above each population during the field sampling in 2012. Second, canopy cover was obtained by remote sensing, using GIS layers (sampled in 2001-2002), to estimate light availability for all pixels of the study area and thus to be able to project SDMs. See Appendix S1 for methodological details about these values (distances, river sinuosity and curvature, canopy cover).

Common climatic variables in SDMs, such as temperature (or elevation) and precipitation, were not included in these models because of the very restricted area with a homogeneous climate.

Quantifying ecological niche separation between species

We performed a Principal Component Analysis, followed by a between-group analysis $\left(\mathrm{PCA}_{\mathrm{b}}\right.$, Dolédec and Chessel 1987) to quantify the separation between the ecological niches of the five species. It consists of a PCA optimised to maximise the variance between a priori determined groups, here the species. $\mathrm{PCA}_{\mathrm{b}}$ is implemented in the ade4 package (Dray and Dufour 2007) of the R software (R Development Core Team 2011) and was applied to the populations observed in 2012, using the complete set of 15 environmental variables in Table S3 to define the multivariate space.

Species distribution models

Species distribution models had two aims: (1) to determine as precisely as possible the ecological preferences of the five invasive species (niche modelling) and (2) to project models in the whole study area in order to visualise and quantify the potential distribution and impact of species colonisation in the whole study area (model projections). Unfortunately, the spatial information about the large majority of the historical populations was not sufficiently precise to fit SDMs based on the 2001 dataset.

We built two different SDMs, by relating (i) the presence or (ii) the abundance (i.e., number of individuals per population) observations recorded in 2012 with 11 environmental variables available as GIS layers (e.g., topography, distances to roads, river sinuosity, Table S3). We also investigated the role of soil variables by adding four field-measured soil variables in separate SDMs. Because these soil variables are not available in a spatially explicit way across the whole study area and because the number of soils sampled as background points to fit the presence model was low (60), we only report in the main article the SDMs based on 11 variables (but see Appendix S2 for SDMs including the soil variables). 
To fit the models, we used custom code in $\mathrm{R}$ and adopted an ensemble approach (Araújo and New 2007) by averaging the results of three commonly used statistical techniques: a generalised linear model (quadratic polynomial GLM; McCullagh and Nelder 1989), a gradient-boosting model (GBM with an interaction depth of 5; Ridgeway 1999; Friedman et al. 2000) and MAXENT with the default settings (Phillips et al. 2006; Elith et al. 2011). Because fewer occurrences were available for the calibration of SDMs for $H$. tuberosus and P. laurocerasus, we ran an initial GBM with the eleven variables and retained in the abundance model only the five and eight most important variables for $H$. tuberosus and P. laurocerasus, respectively.

For the presence model, we selected 10,000 background points across the study area and contrasted them with the species' occurrences. We assumed that our population sampling was exhaustive but we preferred to model species niche with background points rather than "true absences" because it is probable that many observed absences are "not yet invaded" sites (Václavík and Meentemeyer 2009). Because our detected populations were not uniformly distributed in the study area but rather showed a strong bias along the distance to the river, we biased the background sampling using the same distribution along distance to the river as the observed populations. This is similar to the use of a bias file representing the observed plant population density (Merow et al. 2013). For each species, the background data were given the same weight as the presence data. GBM and MAXENT were performed using the package dismo (Hijmans et al. 2011). Only GLM and GBM were used to model abundance, as MAXENT is not suitable for this purpose. Model selection was carried out based on BIC following a forward-backward stepwise procedure using the StepAIC function (Venables and Ripley 2002) and by a k-fold cross-validation function (Elith et al. 2008) in GLM and GBM, respectively. The importance of variables was assessed by estimating the effect of variable randomisation on species suitability predictions following Thuiller et al. (2010).

To assess model predictions, we used the area under the ROC-plot curve (AUC; Fielding and Bell 1997) and the True Skill Statistics (TSS; Allouche et al. 2006), which both evaluate the ability of the model to discriminate presences from background points. AUC varies between 0 (counter-prediction) and 1 (perfect prediction), with 0.5 meaning random predictions. TSS is scaled between -1 and 1 , with 0 meaning random predictions. Although it is common to use "presences-absences" evaluation indices such as AUC and TSS in presence-background models (e.g., Gallien et al. 2012), their use in such contexts can be questioned (Václavík and Meentemeyer 2009; Merow et al. 2013). Thus, we added two presence-only evaluators: the continuous Boyce index (Boyce et al. 2002; Hirzel et al. 2006) and the sensitivity calculated on predictions binarised with the threshold that provided the best TSS. The Boyce index measures how much model predictions differ from the random distribution of the observed presences across the range of prediction values and is analogous to a correlation value, varying between -1 (counter-prediction) and 1 (perfect prediction), with 0 meaning random predictions. The sensitivity is a threshold-dependent evaluator corresponding to the rate of presences correctly classified by the model. For the abundance models, we used Spearman's rank correlation (SC) between the observed and the modelled population sizes. SDMs were evaluated following a random split sampling procedure: $70 \%$ of the data was used for model calibration, and the remaining $30 \%$ was used for model evaluation. This procedure was replicated 10 times, and evaluators were averaged for all models and replicates.

SDMs based on species presences were then projected in order to visualise areas potentially suitable for species colonisation in the whole study area. Then, for each species in each sector $i$, we calculated a potential range-filling index $\left(P R F_{i}\right)$ and an actual range-filling index $\left(A R F_{i}\right)$ :

$\mathrm{PRF}_{\mathrm{i}}=\mathrm{h}_{\mathrm{i}} / \mathrm{h}_{\max }$

$\mathrm{ARF}_{\mathrm{i}}=\left(\mathrm{O}_{\mathrm{i}} / \mathrm{A}_{\mathrm{i}}\right) /(\mathrm{O} / \mathrm{A})_{\max }$

where $h_{i}$ corresponds to the average suitability in sector $i, O_{i}$ to the number of individuals in the sector $i$ and $A_{i}$ to the area of the sector $i$ relatively to most suitable sector $\left(h_{\max }\right)$ and the most invaded sector $(O / A)_{\text {max }}$. Therefore, a high PRF value indicates that the sector contains a large area of suitable habitats that is more susceptible to invasion than other sectors. If coupled with low ARF, it indicates that the sector contains a large area of suitable habitat but few invasive individuals. However, if coupled with high $\mathrm{ARF}$, it indicates that the suitable habitat in the sector 
has already been largely invaded. Thus, sectors with a low difference between PRF and ARF values are closer to saturation than other sectors.

We also projected the abundance SDMs where the species were predicted as potentially present to visualise the potential impact of the species. The continuous suitability of the presence SDMs was reclassified into absences (0) and presences using a threshold that included $95 \%$ of the observed occurrences for each species $\left(\mathrm{MPA}_{95}\right.$, Engler et al. 2004).

\section{Results}

General observations

A total of 984 populations of invasive plants were recorded in the study area during summer 2012, including populations of $R$. japonica $(\mathrm{N}=381), I$. glandulifera $(\mathrm{N}=313), B$. davidii $(\mathrm{N}=147), P$. laurocerasus $(\mathrm{N}=88)$ and H. tuberosus $(\mathrm{N}=54)$. $I$. glandulifera presented the highest proportion of large populations ( $37.06 \%$ in class $5,>100$ individuals), followed by $R$. japonica (12.07\%), H. tuberosus (11.11\%) and P. laurocerasus (2.27\%), whereas $B$. davidii had none. Species density (number of individuals per metre of sector) was the highest, on average, for I. glandulifera (mean $\pm \mathrm{SD}$ : $4.25 \pm 6.12$ ), followed by $R$. japonica $(1.11 \pm 1.35)$, H. tuberosus $(0.13 \pm 0.23), P$. laurocerasus $(0.07 \pm 0.17)$ and $B$. davidii $(0.03 \pm 0.06)$. The total area occupied was $29,804 \mathrm{~m}^{2}$ for I. glandulifera, $22,775 \mathrm{~m}^{2}$ for $R$. japonica, $6545 \mathrm{~m}^{2}$ for B. davidii, $5464 \mathrm{~m}^{2}$ for $P$. laurocerasus and $1089 \mathrm{~m}^{2}$ for $H$. tuberosus.

Changes in invasive species densities

between 2001 and 2012

The changes in sector densities observed between 2001 and 2012 (Fig. S3) were significant for I. glandulifera (Wilcoxon signed rank test: $P$ value $<0.001, \mathrm{~N}=37$; see Table S4 for detailed results of the statistical tests), with an average increase of $1122 \%$, and for $R$. japonica under all three conversions (all three values $<0.001, \quad \alpha_{\text {Bonferroni }}=0.0083, \quad \mathrm{~N}=44$ ), with an increase of $565 \%$ (using the median value). For $B$. davidii, the difference was significant only with the minimum conversion value (minimum conversion value: $P$ value $<0.001, \alpha_{\mathrm{Bonferroni}}=0.0083, \mathrm{~N}=35$; median and maximum conversion values: $P$ value $>0.049$ ), with an average increase of $85 \%$ (median value), whereas there was no significant variation for $H$. tuberosus $(P$ value $=0.58, \mathrm{~N}=28)$. The changes in size of the 2001 populations re-identified in 2012 (Fig. S4) were significant for $I$. glandulifera ( $P$ value $=0.027, \mathrm{~N}=10)$ and for $R$. japonica under all three conversions (all three $P$ values $<0.001, \alpha_{\text {Bonferroni }}$ $=0.0083, \mathrm{~N}=66$ ), but none of the conversions was significant for $B$. davidii (all three $P$ values $>0.049$, $\alpha_{\text {Bonferroni }}=0.0083, \mathrm{~N}=23$ ). P. laurocerasus was not inventoried in 2001, at which time the species was too rare to be considered a problem in regional forests.

Niche separation between species

The three first axes of the initial $\mathrm{PCA}_{\mathrm{b}}$ explained $38.89 \%$ of the total variance (Fig. 2 and S5). The between-species analysis revealed that the position of the niche centroids significantly differed between species (between inertia ratio $=0.07 ; 1000$ randomisation test $P$ value $=0.001)$. $R$. japonica had the widest niche, occupying the median conditions. $P$. laurocerasus and B. davidii occupied more marginal conditions compared to the other species (Fig. 2; Table S5). P. laurocerasus was characterised by more organic soils and greater canopy cover and by proximity to human disturbances (habitations, industries and railways). B. davidii tended to grow in the opposite conditions, i.e., open areas on soils dominated by small stones. Compared to $R$. japonica, $H$. tuberosus was discriminated along the first PCA component as closer to the roads, whereas I. glandulifera was located in environments characterised by a greater river sinuosity and small stones.

Performance of the models

Because the performance of models with 15 variables, including soil variables measured on the field, was not better on average than that of models with 11 spatially explicit variables, we present only the latter here. See Appendix S2 for the results of the 15 variable models. For presence models, AUC ranged between 0.751 and 0.952 , TSS between 0.419 and 0.810 , the Boyce index between 0.361 and 0.982 , and sensitivity between 0.684 and 0.953 (Table 1). Thus, according to the scale of the BIOMOD manual (Thuiller et al. 2010), only $H$. tuberosus shows only "fair" evaluations, 


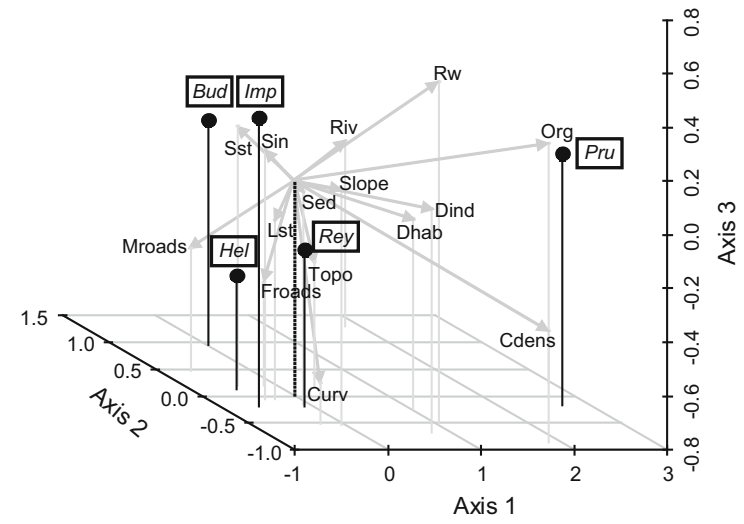

Fig. 2 Principal Components Analysis, followed by a between group analysis $\left(\mathrm{PCA}_{\mathrm{b}}\right)$, based on species presence related to the 15 environmental variables, including variables measured in the field: distances to the river (Riv), major roads (Mroads), forest roads (Froads) and railways (Rw); density of industry (Dind) and habitation (Dhab); slope, topography index (Topo), river sinuosity (Sin), river curvature (Curv), canopy density (Cdens); soil content in organic matter (Org), fine mineral sediments (Sed), small stones (Sst) and large stones (Lst); see Appendix S1 and Table S3 for more details on these variables. The lengths of the vectors represent the magnitude of the correlation between the variables and the axes. The environmental distance between the niche centroid of $R$. japonica (Rey), I. glandulifera (Imp), B. davidii (Bud), H. tuberosus ( $\mathrm{Hel}$ ) and P. laurocerasus (Pru) are given in Table S5. The three first axes of the initial PCA explained $38.89 \%$ of the total variance (axis $1,14.60 \%$; axis 2 , $14.02 \%$; axis $3,10.27 \%$ ). The dashed line connects the origin of this environmental space

while the SDMs for the other species can be considered as "good" to "very good". The results showed greater contrast for the abundance models, where significant correlations (Spearman's rho correlation test: $P$ value $<0.05$; Table 1$)$ were found only for $R$. japonica (0.275) and I. glandulifera (0.480).

Importance of environmental predictors

The importance of the 11 environmental predictors used in the SDMs (see Appendix S2 for the 15 variable models) varied between species and models (Fig. 3). Predictors that consistently better explained species distributions for the presence models were the distance to the river and the canopy density. Indeed, all the species were modelled as close to the river under open canopy, except $P$. laurocerasus, which followed the opposite trend. The density of habitations was also an important predictor for R. japonica, I. glandulifera and $B$. davidii, all predicted in areas with high habitation densities. River curvature was important to depict $H$. tuberosus distribution, modelled as growing on the internal shore of the meanders (Appendix S3). Models including field data suggested that soil variables could be important to model species occurrences, in particular for I. glandulifera, $P$. laurocerasus and $H$. tuberosus. For this last species, AUC was increased up to 0.88 with these supplementary variables, allowing it to be considered a good model (Appendix S2), although it must be interpreted with caution because of the low number of available occurrences (54).

The predictor that best explained the abundance of the two species with significant models ( $R$. japonica, $I$. glandulifera) was canopy density, with higher abundance of the species in open areas. Roads also influenced both species, with higher abundance farther from forest roads for $R$. japonica and at a distance of approximately $200 \mathrm{~m}$ from major roads for I. glandulifera. River curvature was also important for explaining I. glandulifera abundance, with higher plant covers along inside meanders (Appendix S4). When included in the modelling of abundance, soil variables were not retained as important variables for $R$. japonica and I. glandulifera and did not improve the poor performance of the models for the other three species (Appendix S2).

There was also a significant correlation between the importance of the variables for the two modelling approaches for $R$. japonica, I. glandulifera and $B$. davidii (Table S6), suggesting that similar ecological processes govern both suitability and demographic processes for these species.

\section{Predictions of invasion risks}

The projection of SDM allowed the prediction of the potential suitable habitats for presences and the potential abundances at a very fine scale (see examples in Fig. 4). At the sector level, The PRF calculated for each sector on the basis of the species' occurrence projections indicated the sectors that were the most susceptible to colonisation by the species (Fig. 5). Coupling this index with the ARF values for 2001 and 2012 allowed the visualisation of the invasion stages for each sector along the river. The distribution patterns of $R$. japonica, I. glandulifera, H. tuberosus and B. davidii observed in 2012 indicated that these species were found together relatively often in the same sectors. Comparing the 
Table 1 Performance of the species presence and abundance models under several evaluators as the average of ten replicates

\begin{tabular}{llllllll}
\hline Model type & Evaluators & Species & & & \\
\cline { 3 - 7 } & & R. japonica & I. glandulifera & B. davidii & H. tuberosus & P. laurocerasus \\
\hline Presence (GLM, GBM, & AUC & $0.839 \pm 0.016$ & $0.889 \pm 0.014$ & $0.856 \pm 0.028$ & $0.751 \pm 0.040$ & $0.952 \pm 0.011$ \\
MAXENT) & TSS & $0.552 \pm 0.037$ & $0.635 \pm 0.035$ & $0.572 \pm 0.049$ & $0.419 \pm 0.025$ & $0.810 \pm 0.042$ \\
& Boyce & $0.982 \pm 0.009$ & $0.934 \pm 0.008$ & $0.941 \pm 0.030$ & $0.361 \pm 0.252$ & $0.841 \pm 0.108$ \\
Abundance (GLM, GBM) & Sensitivity & $0.835 \pm 0.042$ & $0.917 \pm 0.022$ & $0.840 \pm 0.072$ & $0.684 \pm 0.141$ & $0.953 \pm 0.037$ \\
& SC & $\mathbf{0 . 2 7 5} \pm \mathbf{0 . 0 9 2}$ & $\mathbf{0 . 4 8 0} \pm \mathbf{0 . 0 6 2}$ & $0.109 \pm 0.161$ & $0.066 \pm 0.202$ & $0.231 \pm 0.130$ \\
\hline
\end{tabular}

Eleven environmental variables were used (see Table S3). Presence models were built with three algorithms (GLM, GBM and MAXENT) under binomial distributions and were evaluated with two presence-background evaluators (AUC, TSS) and two presence-only evaluators (Boyce, Sensitivity). Abundance models were built with two algorithms (GLM and GBM) under Poisson distributions and were evaluated using Spearman's rank correlation (SC, bold type indicates significant correlation)

Fig. 3 Importance (assessed by permutation, see methods) of the 11 variables used in the SDMs for species presence (upper panel) and species abundance (lower panel). See Fig. 2 for abbreviations and Appendix S1 and Table S3 for more details on these variables. Note that for B. davidii, H. tuberosus and $P$. laurocerasus, the abundance model may not be ecologically relevant
R. japonica
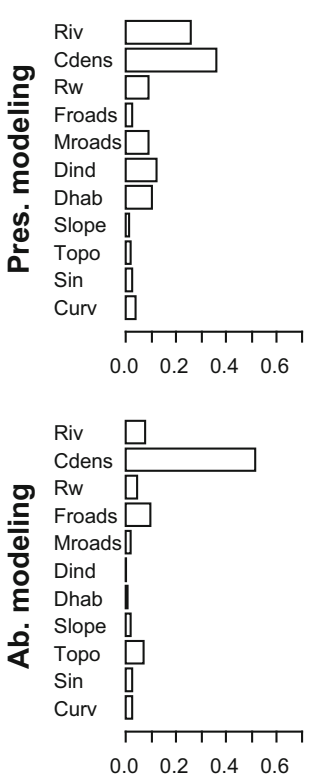

$\begin{array}{llll}0.0 & 0.2 & 0.4 & 0.6\end{array}$
I. glandulifera

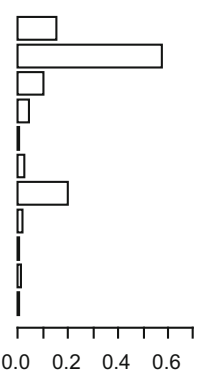

B. daviidi


Relative importance
H. tuberosus P. laurocerasus
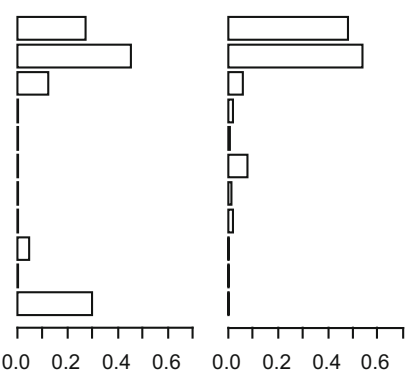

2001 ARF to the 2012 ARF shows that all species invaded new sectors, and the differences between the PRF and ARF values show that large areas are still available for future colonisation by each species (Fig. 5). We also measured the change in the species' densities relative to those observed in 2001; globally, most of the sectors showed increased density of the invasive species. Important decreases in densities were observed only for $B$. davidii (e.g., sectors 16, 23 and 40 in Fig. 5) and H. tuberosus (e.g., sectors 26, 27 and 31; Appendix S8). These sectors were also the ones presenting the greatest increases in I. glandulifera and $R$. japonica.

\section{Discussion}

Overall, our study revealed a very important increase in invasive plant species along the Venoge River over a period of 11 years. We were able to successfully model their ecological niches and to project the distribution of their potentially suitable areas at a very 
Fig. 4 Mapped scores of the modelled habitat suitability for the occurrence (continuously varying between 0 and 1 , first line) and abundance (second line) along the Venoge River (sectors 21-24). Scores were obtained by averaging all of the single-model projections (ensemble function). High suitability scores indicate that the habitat is favourable for the presence of the species. Abundance is reported only for the two species for which the models are significant ( $I$. glandulifera and $R$. japonica). To delimit the area that is not suitable for species growth, we used the values provided by the suitability models, which include $95 \%$ of the observed populations. The size class of the observed populations is also reported (circles). See Fig. S5 for the non-significant abundance models and the suitability models for I. glandulifera and $R$. japonica $\begin{array}{lll}\text { B. daviidi } & \text { P. Laurocerasus } \quad H \text {. tuberosus }\end{array}$


Observed populations

- 1-5 (class 1$)$

- 6-10 (class 2)

- 11-50 (class 3)

○ 51-99 (class 4)

$0 \geq 100$ (class 5)

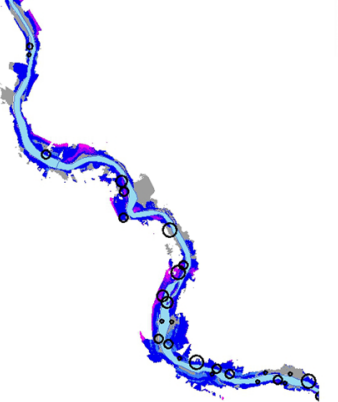

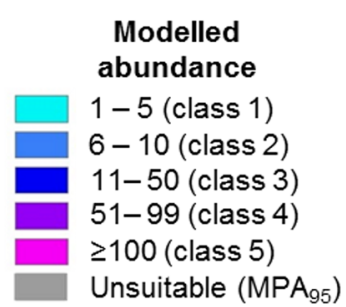

high resolution across the entire study area. From these results, we measured potential range-filling (PRF) coupled with actual range-filling (ARF) per sector, which together showed that large areas of suitable habitat for each species may remain to be colonised, despite the existing abundance of some of the species in the study area. For two of the species $(R$. japonica and I. glandulifera), we were also able to obtain SDMs for species abundance, which may be further used as a proxy for their potential impact on native species.

\section{Species environmental preferences}

The evaluations of SDMs based on species' presences varied between good and very good (except for $H$. tuberosus, with only fair models), which is very satisfying for modelling at such a fine resolution. Indeed, it has been shown that refining the grain size may negatively affect evaluators such as AUC for tree species (Seo et al. 2009). Maintaining good evaluation at a resolution of $1 \mathrm{~m}$ thus provides good support for the validity of the models and their spatial predictions. Moreover, the abiotic environmental preferences highlighted by our models are generally consistent with literature on the ecology of these species. SDMs for abundance were less successful, with significant correlations for only two species. For the other species, the low number of occurrences ( $P$. laurocerasus), a possible distributional disequilibrium (i.e., species having not yet colonised all suitable sites or reached their carrying capacity) or important missing variables, such as soil $\mathrm{pH}$ or soil temperature, may explain the low predictive accuracy of the abundance models. The uncertainty of the elevation DEM $( \pm 0.5 \mathrm{~m})$ may also explain why the topographic index is not more important in our models. Note that the environmental variables were weakly cross-correlated, which supported our choice to include 

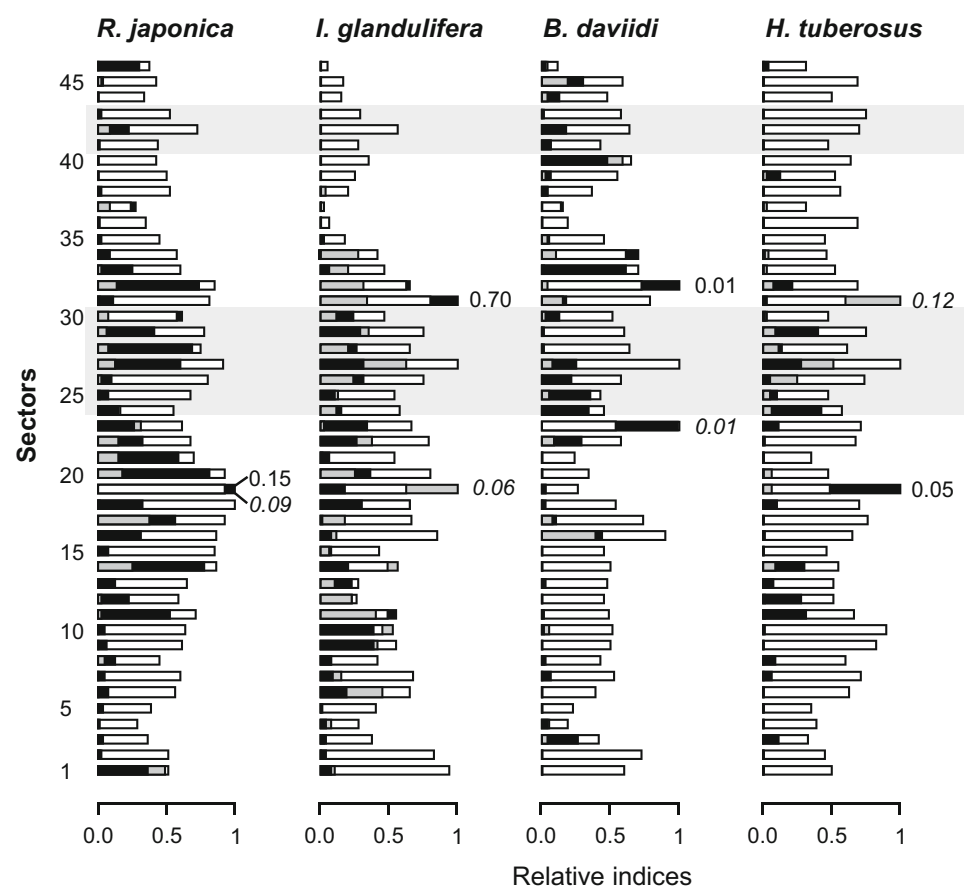

P. laurocerasus

Relative indices

Fig. 5 Stacking of the potential range-filling index (PRF, white bars) and actual range-filling index (ARF) for 2001 (grey bars) and 2012 (black bars) along 46 sectors of the Venoge River from Cossonay (sector 46, see Fig. 1) to Lake Geneva (sector 1). The PRF values correspond to the relative amount of suitable habitat present in each sector, and the ARF values correspond to the

them in the approach for the SDMs (see Table S7 for the complete correlations between variables).

The $\mathrm{PCA}_{\mathrm{b}}$ and the modelling of suitability for presence with the 15 predictors (see Appendix S2) showed that the variables related to soil characteristics may be important for precisely describing the realised niches of some of the species (H. tuberosus). Unfortunately, these variables are too rarely included in models (e.g. Bio et al. 2002; Dubuis et al. 2013), due to the difficulty of producing spatially explicit maps. However, the fact that we can obtain good results for most species without including soil characteristics measured in the field suggests that variables such as distance to river and river curvature may act as good proxies for soil properties in alluvial areas. Flood disturbances disperse plant diaspores (Pysek and Prach 1993; Tickner et al. 2001), erode river margins, deposit mineral sediments and create openings in the forb or tree cover, microhabitats favourable for seed germination (Renöfält et al. 2005; Maskell et al. 2006; Miller and Matlack 2010). The disturbances therefore observed relative species density. For each species, values next to the bars correspond to the absolute density (individuals $/ \mathrm{m}^{2}$ ) of the most invaded sectors in 2001 (in italics) and 2012. No data were available for $P$. laurocerasus in 2001 . The protected areas are shaded (sectors 41-43 and 24-30)

create good opportunities for the establishment of invasive species by increasing light availability, soil resources and reducing species competition (Davis et al. 2000; Miller and Matlack 2010), which explains why invasive species are widespread along river corridors (Renöfält et al. 2005). Consistent with these observations, our models showed that $R$. japonica, $I$. glandulifera, $B$. davidii and $H$. tuberosus prefer sites with high light availability, close to the river that creates new primary areas by meander expansion and diaspore deposition with sediments. However, $B$. davidii is more tolerant to drought and prefers stonier soils than $R$. japonica, I. glandulifera and H. tuberosus, which are found on moist sediment and nutrient rich soils (Wyse et al. 1986; Barney et al. 2006; Pysek et al. 2012).

Interestingly, light availability appears to have a lower influence on occurrences than on the abundance of $R$. japonica (Fig. 3), suggesting that this species can grow in areas with variable light regimes but finds optimal growth conditions in open areas. Thus, the 
possible colonisation of shaded habitats outside floodplains is not excluded, as observed regularly for $R$. japonica (Pysek et al. 2012). Conversely, our results suggest that river curvature did not influence the habitat suitability of I. glandulifera, but this variable ranked second most important in the abundance model. This means that the quiet conditions inside the river meanders are particularly ideal for the development of large populations. Although there is high suitability all along the study area for $I$. glandulifera, the upstream part of the river (sectors 35-46) is less invaded than the downstream sectors (1-35), suggesting an initial introduction near the village of Vufflens-la-ville (sector 35; see ARF values; Fig. 5) and later downstream dispersal, underlining the possible importance of river dispersal (Pysek and Prach 1993).

By mostly colonising shaded understory conditions, the ecological niche of $P$. laurocerasus is the most isolated one, compared to the other species. It is a highly shade-tolerant species, an uncommon characteristic among native woody species (Landolt et al. 2010), and it depends on dispersal by birds (Richardson et al. 2000), especially Turdus merula, a very common bird in Swiss forests (Glutz Von Blotzheim 1988). The recent success of this species at invading such conditions may be linked to climate warming, as has been shown for the shrub layer in Switzerland (Walther et al. 2002).

Population number and size changes

Our study showed sharp increases in the population number and size of $I$. glandulifera and $R$. japonica between 2001 and 2012 at the local scale, whereas populations of $B$. davidii only increased at some locations, and $H$. tuberosus decreased overall. This overall increase is consistent with the important spread of I. glandulifera and $R$. japonica observed across Europe at the regional or country scale (e.g., Pysek and Prach 1993; Pysek and Hulme 2005). However, we are not aware of any study that has investigated the population number and size changes of $B$. davidii and H. tuberosus in Europe.

At the habitat level, high native species diversity leads to better resistance to invasive species because few resources remain available to support the establishment and growth of additional species (Maskell et al. 2006; Eschtruth and Battles 2009). However, flood disturbances are favourable for seed germination and lead to an increase in available resources for which native and invasive species compete (Davis et al. 2000). Thus, invasion success will depend on the potential of species to colonise new habitats (e.g., high dispersal efficiency, high seedbank persistence, high abundance of the species in the vicinity) and to outcompete the native species (e.g., rapid growth, high faculty for regeneration; Tickner et al. 2001; Lake and Leishman 2004). I. glandulifera and $R$. japonica exhibit some of these characteristics: annual rapid growth on disturbed open soils, many persistent seeds for I. glandulifera (Perrins et al. 1993), and vigorous growth and vegetative spread, with a high faculty for regeneration for $R$. japonica (Bimova et al. 2004). The high competitive ability (e.g., shading out native species) resulting from these characteristics may explain their increases in population number and size observed between 2001 and 2012.

However, intense river flooding can also have a negative effect on the dynamics of invasive species. Kasperek (2004) noted that the cover of annual $I$. glandulifera was negatively affected by flooding occurring during the germination period (MarchApril), and, conversely, populations increased during dry periods. Interestingly, by comparing I. glandulifera densities (2001 and 2012) to hydrological patterns of the river (Fig. S7), we observed that heavy flooding occurred during spring 2001, whereas no major flooding occurred after 2007. Hence, the strong population increase may be related in part to interannual fluctuations of river flow. This influence of flooding on species abundance may explain the preference of the species for the inner side of the meander that was observed with the abundance models.

B. davidii may also have suffered from this decrease in flooding events, as it is known to grow rapidly in disturbed areas (Tallent-Halsell and Watt 2009) but is intolerant of shade, and natural vegetation succession may lead to its elimination in the absence of disturbance (Tallent-Halsell and Watt 2009). The low flood frequency (Fig. S7) in recent years may explain the slower spread observed for this species between 2001 and 2012. However, given the lack of temporal data, further observations would be necessary to better characterise the dynamics of this species in our study area before drawing any firm conclusions. Note that optimal conditions for $B$. davidii, 
characterised by stony soils, may be rarer than fine mineral sediment environments along the Venoge, thus limiting the population number of this species.

$H$. tuberosus grows rapidly, spreads vegetatively and has a high faculty for regeneration as well (Swanton et al. 1992), but it showed a population size decline in our study area between 2001 and 2012. Moreover, we observed that some populations recorded in 2001 have been reduced in size and were replaced by dense populations of I. glandulifera or $R$. japonica in 2012. Indeed, sectors where H. tuberosus was very abundant in 2001 (i.e., sectors 26, 27, 28 and 31 ) correspond to those in which I. glandulifera and $R$. japonica densities have increased sharply and are now very abundant (see ARF values; Fig. 5). This suggests a possible competition for suitable habitats among $I$. glandulifera, $R$. japonica and H. tuberosus, a proposition that is also supported by their similar environmental requirements (Fig. 2 and S3; Table S5).

\section{Predicted distributions and derived indices}

The very high resolution $(1 \mathrm{~m} \times 1 \mathrm{~m})$ used in our models allowed us to capture at the plant scale several important microhabitat variables (e.g., light availability, distance to disturbances, river curvature) varying significantly over short distances along rivers. Such habitat variables are better translated at such a fine resolution than with a coarser resolution (e.g., 25 or $100 \mathrm{~m}$ ), where, for example, light availability under the canopy cannot be extracted, and river sinuosity would be meaningless with a resolution exceeding river width.

From our spatial predictions, we could derive the potential range filling for the different river sectors (Fig. 5). Meanwhile, historical, recent and precise field inventories allowed us to evaluate the colonised areas in the past and present, expressed as the actual range filling for each river sector. The combination of the two indices shows the colonisation potential of the invasive species at the local scale in the future and could be used more systematically in conservation plans along rivers to rationalise control and prioritise eradication efforts. For example, to eradicate problematic source populations, eradication could focus on sectors presenting highly suitable conditions (i.e., high PRF) and already colonised, possibly acting as population sources for downstream sectors (e.g., sector 32 for I. glandulifera and R. japonica, located upstream from the protected area; Fig. 5) or to limit the local development where very suitable conditions are present. On the other hand, observation efforts could be prioritised in suitable (i.e., high PRF) but unfilled sectors (i.e., low ARF), such as sector 16 for $I$. glandulifera or sector 35, upstream from the protected area, for $R$. japonica. Note that sometimes (e.g., sector 31 for I. glandulifera; Fig. 5), actual range filling is higher than potential range filling, designating sectors of the river that are particularly saturated in regard to the potential distribution of the species. Additionally, these indices could be coupled with the modelled abundance, adding a supplementary priority level based on the potential impact of invasive populations. Finally, empty sectors with a high suitability may also reflect areas that were not invaded due to other factors not considered in the SDMs (e.g., the presence of some dominant native species, dispersal limitations, destruction of populations by floods). Only supplementary measurements (e.g., exhaustive list of the native species in these places, tree and shrubs covers, river flow during a flood) would elucidate the cause of this pattern.

Although it is an area of high conservation value, no management plan currently exists for the study area. The combination of the measured dramatic population increases of these invasive species along the river, mapped invasion risks and a sector-by-sector prioritisation plan may provide valuable support for elaborating future conservation planning for this study area.

Suitable habitats still appear to be largely available for each species from the prediction maps, suggesting that the observed increase in invasive species may continue in the coming years. However, these predicted areas only represent potential scenarios, and it remains impossible to use an empirical modelling approach like this one to assess whether or not the species have reached their environmental equilibrium (i.e., have colonised all their potentially suitable environmental conditions). Although the very important increases in $R$. japonica and I. glandulifera populations between 2001 and 2012 suggests that they now more completely occupy their potential habitat along the Venoge River, only future inventories will allow testing whether these species have reached their niche equilibrium. Meanwhile, our approach provides spatially explicit information about the current status and 
future risk of invasions and should help with the management of invasive plant species at a very local scale.

Acknowledgments Thanks to Stuart Lane and Nathalie Diaz for their assistance with soil sample analysis, Anne Freitag and the Zoological Museum of Lausanne for the loan of the spherical densiometer, and Robin Gray, Anne-Béatrice Dufour, Jérôme Pellet, Joslin Moore and two anonymous reviewers for their helpful comments on previous drafts.

\section{References}

Allouche O, Tsoar A, Kadmon R (2006) Assessing the accuracy of species distribution models: prevalence, kappa and the true skill statistic (TSS). J Appl Ecol 43:1223-1232

Araújo MB, New M (2007) Ensemble forecasting of species distributions. Trends Ecol Evol 22:42-47

Barney JN, Tharayil N, DiTommaso A, Bhowmik PC (2006) The biology of invasive alien plants in Canada. 5. Polygonum cuspidatum Sieb. \& Zucc. [= Fallopia japonica (Houtt.) Ronse Decr.]. Can J Plant Sci 86:887-905

Bimova K, Mandak B, Kasparova I (2004) How does Reynoutria invasion fit the various theories of invasibility? J Veg Sci 15:495-504

Bio AM, De Becker P, De Bie E et al (2002) Prediction of plant species distribution in lowland river valleys in Belgium: modelling species response to site conditions. Biodivers Conserv 11:2189-2216

Boyce MS, Vernier PR, Nielsen SE, Schmiegelow FK (2002) Evaluating resource selection functions. Ecol Modell 157:281-300. doi:10.1016/S0304-3800(02)00200-4

Bradley BA (2013) Distribution models of invasive plants overestimate potential impact. Biol Invasions 15:1417-1429

Burkart M (2001) River corridor plants (Stromtalpflanzen) in central European lowland: a review of a poorly understood plant distribution pattern. Glob Ecol Biogeogr 10:449-468

Davis MA, Grime JP, Thompson K (2000) Fluctuating resources in plant communities: a general theory of invasibility. J Ecol 88:528-534

Dolédec S, Chessel D (1987) Rythmes saisonniers et composantes stationnelles en milieu aquatique. I: description d'un plan d'observation complet par projection de variables. Acta Oecol 8:403-426

Dray S, Dufour AB (2007) The ade4 package: implementing the duality diagram for ecologists. J Stat Softw 22:1-20

Dubuis A, Giovanettina S, Pellissier L et al (2013) Improving the prediction of plant species distribution and community composition by adding edaphic to topo-climatic variables. J Veg Sci 24:593-606

Ehrenfeld JG (2003) Effects of exotic plant invasions on soil nutrient cycling processes. Ecosystems 6:503-523

Elith J, Leathwick JR, Hastie T (2008) A working guide to boosted regression trees. J Anim Ecol 77:802-813

Elith J, Phillips SJ, Hastie T et al (2011) A statistical explanation of MaxEnt for ecologists. Divers Distrib 17:43-57

Engler R, Guisan A, Rechsteiner L (2004) An improved approach for predicting the distribution of rare and endangered species from occurrence and pseudo-absence data. J Appl Ecol 41:263-274

Eschtruth AK, Battles JJ (2009) Assessing the relative importance of disturbance, herbivory, diversity, and propagule pressure in exotic plant invasion. Ecol Monogr 79:265-280

Fielding AH, Bell JF (1997) A review of methods for the assessment of prediction errors in conservation presence/ absence models. Environ Conserv 24:38-49

Friedman J, Hastie T, Tibshirani R (2000) Additive logistic regression: a statistical view of boosting. Ann Stat 28:337-407

Gallien L, Douzet R, Pratte S et al (2012) Invasive species distribution models-how violating the equilibrium assumption can create new insights. Glob Ecol Biogeogr 21:1126-1136

Growns I, Rourke M, Gilligan D (2013) Toward river health assessment using species distributional modeling. Ecol Indic 29:138-144

Guillera-Arroita G, Hauser CE, Mccarthy MA (2014) Optimal surveillance strategy for invasive species management when surveys stop after detection. Ecol Evol 4:1751-1760

Guisan A, Thuiller W (2005) Predicting species distribution: offering more than simple habitat models. Ecol Lett 8:993-1009

Guisan A, Tingley R, Baumgartner JB et al (2013) Predicting species distributions for conservation decisions. Ecol Lett 16:1424-1435

Heinänen S, Erola J, Von Numers M (2012) High resolution species distribution models of two nesting water bird species: a study of transferability and predictive performance. Landsc Ecol 27:545-555

Hijmans RJ, Phillips S, Leathwick J, Elith J (2011) Dismo: Species distribution modeling. R package version $0.7-17$. http://cran.r-project.org/package=dismo

Hirzel AH, Le Lay G, Helfer V et al (2006) Evaluating the ability of habitat suitability models to predict species presences. Ecol Modell 199:142-152

Hulme PE (2003) Biological invasions: winning the science battles but losing the conservation war? Oryx 37:178-193

Kasperek G (2004) Fluctuations in numbers of neophytes, especially Impatiens glandulifera, in permanent plots in a west German floodplain during 13 years. NEOBIOTA 3:27-37

Keller CA, Hill M, Vollmer MK et al (2012) European emissions of halogenated greenhouse gases inferred from atmospheric measurements. Environ Sci Technol 46:217-225

Koop AL, Fowler L, Newton LP, Caton BP (2012) Development and validation of a weed screening tool for the United States. Biol Invasions 14:273-294

Kremen C, Cameron A, Moilanen A et al (2008) Aligning conservation priorities across taxa in Madagascar with high-resolution planning tools. Science (80-) 320:222-226

Kulhanek SA, Leung B, Ricciardi A (2011) Using ecological niche models to predict the abundance and impact of invasive species: application to the common carp. Ecol Appl 21:203-213

Lachat T, Pauli D, Gonseth Y et al (2010) Wandel der Biodiversität in der Schweiz seit 1990, Ist die Talsohle erreicht?. Haupt Verl, Berne

Lahoz-Monfort JJ, Guillera-Arroita G, Wintle BA (2014) Imperfect detection impacts the performance of species distribution models. Glob Ecol Biogeogr 23:504-515 
Lake JC, Leishman MR (2004) Invasion success of exotic plants in natural ecosystems: the role of disturbance, plant attributes and freedom from herbivores. Biol Conserv 117:215-226

Landolt E, Bäumler B, Erhardt A, et al. (2010) Flora Indicativa. Ecological indicator values and biological attributes of the Flora of Switzerland and the Alps, Haupt Verl. Berne

Leung B, Lodge DM, Finnoff D et al (2002) An ounce of prevention or a pound of cure: bioeconomic risk analysis of invasive species. Proc R Soc 269:2407-2413

Maskell LC, Bullock JM, Smart SM et al (2006) The distribution and habitat associations of non-native plant species in urban riparian habitats. J Veg Sci 17:499-508

McCarthy MA, Moore JL, Morris WK et al (2013) The influence of abundance on detectability. Oikos 122:717-726

McCullagh P, Nelder JA (1989) Generalized linear models, 2nd edn. Chapman and Hall, London

Merow C, Smith MJ, Silander JA (2013) A practical guide to MaxEnt for modeling species' distributions: what it does, and why inputs and settings matter. Ecography (Cop) 36:1058-1069

Miller NP, Matlack GR (2010) Population expansion in an invasive grass, Microstegium vimineum: a test of the channelled diffusion model. Divers Distrib 16:816-826

Morard E (2001) Cartographie et état actuel de quatre plantes potentiellement invasives le long de la Venoge. Master report, University of Lausanne (Unpublished)

Perrins J, Fitter A, Williamson M (1993) Population biology and rates of invasion of three introduced Impatiens species in the British Isles. J Biogeogr 20:33-44

Phillips SJ, Anderson RP, Schapire RE (2006) Maximum entropy modeling of species geographic distributions. Ecol Modell 190:231-259

Pysek P, Hulme PE (2005) Spatio-temporal dynamics of plant invasions: linking pattern to process. Ecoscience 12:302-315

Pysek P, Prach K (1993) Plant invasions and the role of riparian habitats: a comparison of four species alien to central Europe. J Biogeogr 20:413-420

Pysek P, Chytry M, Pergl J et al (2012) Plant invasions in the Czech Republic: current state, introduction dynamics, invasive species and invaded habitats. Preslia 84:575-629

R Development Core Team (2011) R: a Language and Environment for Statistical Computing. The R Foundation for Statistical Computing, Vienna

Renöfält BM, Jansson R, Nilsson C (2005) Spatial patterns of plant invasiveness in a riparian corridor. Landsc Ecol 20:165-176

Ricciardi A (2003) Predicting the impacts of an introduced species from its invasion history: an empirical approach applied to zebra mussel invasions. Freshw Biol 48: 972-981

Richardson DM, Allsopp N, D’Antonio CM et al (2000) Plant invasions - the role of mutualisms. Biol Rev Camb Philos Soc 75:65-93

Ridgeway G (1999) The state of boosting. Comput Sci Stat 31:172-181

Seo C, Thorne JH, Hannah L, Thuiller W (2009) Scale effects in species distribution models: implications for conservation planning under climate change. Biol Lett 5:39-43

Swanton CJ, Cavers PB, Clements DR, Moore MJ (1992) The biology of Canadian weeds. 101. Helianthus tuberosus L. Can J Plant Sci 72:1367-1382

Tallent-Halsell NG, Watt MS (2009) The invasive Buddleja davidii (Butterfly bush). Bot Rev 75:292-325

Thuiller W, Richardson DM, Pysek P et al (2005) Niche-based modelling as a tool for predicting the risk of alien plant invasions at a global scale. Glob Chang Biol 11:2234-2250

Thuiller W, Lafourcade B, Araujo M (2010) Presentation manual for BIOMOD. University Joseph Fourier, Laboratoire d'écologie Alpine, Grenoble

Tickner DP, Angold PG, Gurnell AM, Mountford JO (2001) Riparian plant invasions: hydrogeomorphological control and ecological impacts. Prog Phys Geogr 25:22-52

Václavík T, Meentemeyer RK (2009) Invasive species distribution modeling (iSDM): are absence data and dispersal constraints needed to predict actual distributions? Ecol Modell 220:3248-3258

Venables WN, Ripley BD (2002) Modern applied statistics with S, 4th edn. Springer, New York

Vicente J, Randin CF, Gonçalves J et al (2011) Where will conflicts between alien and rare species occur after climate and land-use change? A test with a novel combined modelling approach. Biol Invasions 13:1209-1227

Von Blotzheim UNG (1988) Handbuch der Vögel Mitteleuropas Band 11/II. AULA-Verlag, Wiesbaden

Walther G, Post E, Convey P et al (2002) Ecological responses to recent climate change. Nature 416:389-395

Ward JV, Tockner K, Arscott DB, Claret C (2002) Riverine landscape diversity. Freshw Biol 47:517-539

Wyse DL, Young FL, Jones RJ (1986) Influence of Jerusalem Artichoke (Helianthus tuberosus) density and duration of interference on soybean (Glycine max) growth and yield. Weed Sci 34:243-247

Zweig MH, Campbell G (1993) Receiver-operating Characteristic (ROC) plots: a fundamental evaluation tool in clinical medicine. Clin Chem 39:561-577 